Western University Scholarship@Western

Research Program. Impact of the Public Sector on Research Program. Impact of the Public Sector on Local Economies Discussion Papers

Local Economies

1977

\title{
The Crunch, the Boom, and the Recreational Land Market
}

Arthur J. Robson

David T. Scheffman

Follow this and additional works at: https://ir.lib.uwo.ca/economicsipsle_dp

Part of the Economics Commons

\section{Citation of this paper:}

Robson, Arthur J., David T. Scheffman. "The Crunch, the Boom, and the Recreational Land Market." Research Program. Impact of the Public Sector on Local Economies Discussion Papers, 016. London, ON: Department of Economics, University of Western Ontario (1977). 


\section{Discussion Paper 016}

THE CRUNCH, THE BOOM, AND THE

RECREATIONAL LAND MARKET

Arthur J. Robson

David T. Scheffman

\section{RESEARCH PROGRAM: IMPACT OF THE PUBLIC SECTOR ON LOCAL ECONOMIES}

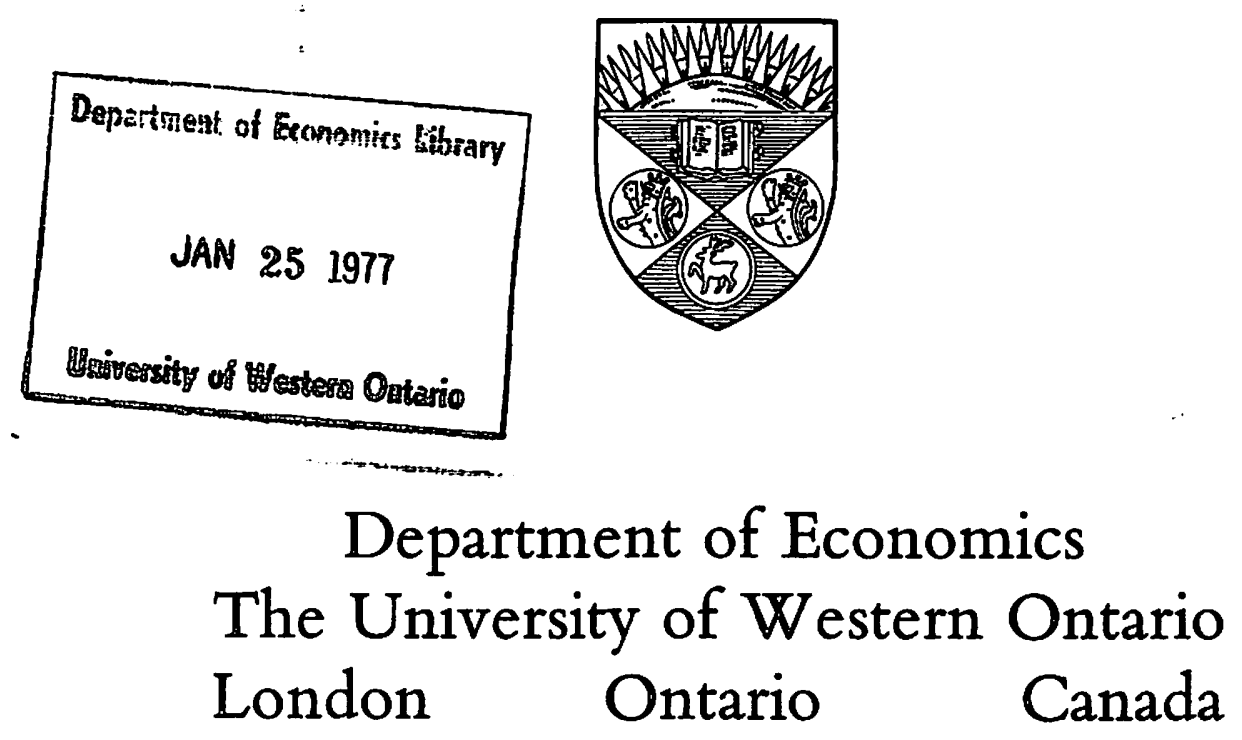




\section{Discussion Paper 016}

THE CRUNCH, THE BOOM, AND THE RECREATIONAL LAND MARKET

Arthur J. Robson

David T. Scheffman

January 1977 
THE CRUNCH, THE BOOM, AND THE

\title{
RECREATIONAL LAND MARKET ${ }^{\star}{ }^{\dagger}$
}

\author{
Arthur J. Robson \\ David T. Scheffman
}

\section{Introduction}

In this paper we will develop a theory of the determination of recreational land prices with particular attention devoted to the roles of transportation costs (gasoline prices), and urban land prices. Using this theory we will then undertake an empirical investigation of the effects of the "energy crunch" and the recent urban real estate "boom" on recreational land prices, using data collected from Registry records on Ontario lake-front property. Our theoretical and empirical analyses will then allow us to make some general inferences about the long run elasticity of demand for recreational travel with respect to gas price, where by "long run" we mean a period long enough for land prices to adjust to the effects of energy price increases.

Intuition would suggest that the more responsive are land prices to changes in travel costs, the less responsive will travel be to such changes. Part of our theoretical analysis is focussed on determining the validity of this intuitive conjecture. Our empirical analysis is then directed to determining the extent to which recreational land prices in Ontario have adjusted to the "energy crunch." Our research has two important policy implications. First we will be able to evaluate the likely impact of the "energy crunch" on the important tourist industry in Canada. The idea here 
is that if our conjecture is correct, the more recreational land prices respond to increased energy prices, the less net effect there will be on tourism. Second, our research will provide a general indication of the likely effects of an eventual government policy of allowing gasoline prices to rise to world levels.

Although we will refer to the consumers in our theoretical models as "cottagers," it should be clear to the reader that our results are applicable to the general case of all types of recreational travel. This is because a change in recreational land prices will be reflected in campground, resort, and motel rents, just as in cottage lots.

\section{Two Models of the Recreational Land Market}

\section{A. A Simple Partial Equilibrium Model}

Let us consider the demand of some consumers for recreational 1 and at some particular location. The consumer derives satisfaction from owning recreational land through the flow of services the land provides him. These services are only available during the time he is occupying the land, and so he must travel to the land to consume its services. Therefore the relevant cost to the consumer of consuming recreational land is the implicit rent on the land plus the cost of making the round $\operatorname{trip}(s)$ to the land. The implicit rent on the land will be $i \cdot \underline{P}$ where $\underline{P}$ is the price per unit of the land and $\underline{i}$ is the opportunity cost interest rate per unit of time. If $T$ is the transportation cost then the demand for recreational land at a particular location by consumer $k, D_{k}$, can be written $D_{k}=D_{k}(i \cdot P+T)$. If all consumers of 1 and at the particular location live at approximately the same distance from this land, their transportation costs will be 
approximately the same. Then, assuming their opportunity cost interest rates are approximately equal, we can write the total demand for 1 and at the location, $D$, as $D=D(i \cdot P+T)$.

Since the amount of land available at any location is fixed, the supply of such land will be as in Figure I, where the supply curve becomes completely inelastic at some price $\bar{P}$, at which the total amount of land, $\bar{L}$, is supplied. At any price above $\bar{P}$ in Figure $I$ suppliers of 1 and are receiving capitalized Ricardian rents equal to the difference between the price and $\bar{P}$.

Now let us consider the effect of a change in the cost of travel, due to, for example, a change in gasoline prices. An increase in travel costs of $\Delta T$ shifts the demand curve down vertically by $\Delta T / i$. If the demand curve is such as $D_{1}$ in Figure $I$, as long as $\Delta T / i \leqq P_{1}-\bar{P}$, the equilibrium price of land will fall by $\Delta T / i$, but the amount of land sold and therefore the total amount of travel does not change. Therefore this simple model predicts that if Ricardian rents are earned before and after a change in travel costs, the change in travel costs is fully "decapitalized" in land prices, and there is no effect on either the amount of land sold or the amount of travel. However, if the new equilibrium price is below $\bar{P}$, such as with demand curve $D_{2}$ in Figure $I$, then the amount of 1 and sold and the amount of travel will fall.

We see that this simple model confirms our intuitive notion that the more responsive travel will be to such changes.

\section{B. A General Equilibrium Spatial Model}

The greatest defect in the simple model of the previous section is that it ignores the fact that there is recreational land at various locations, 


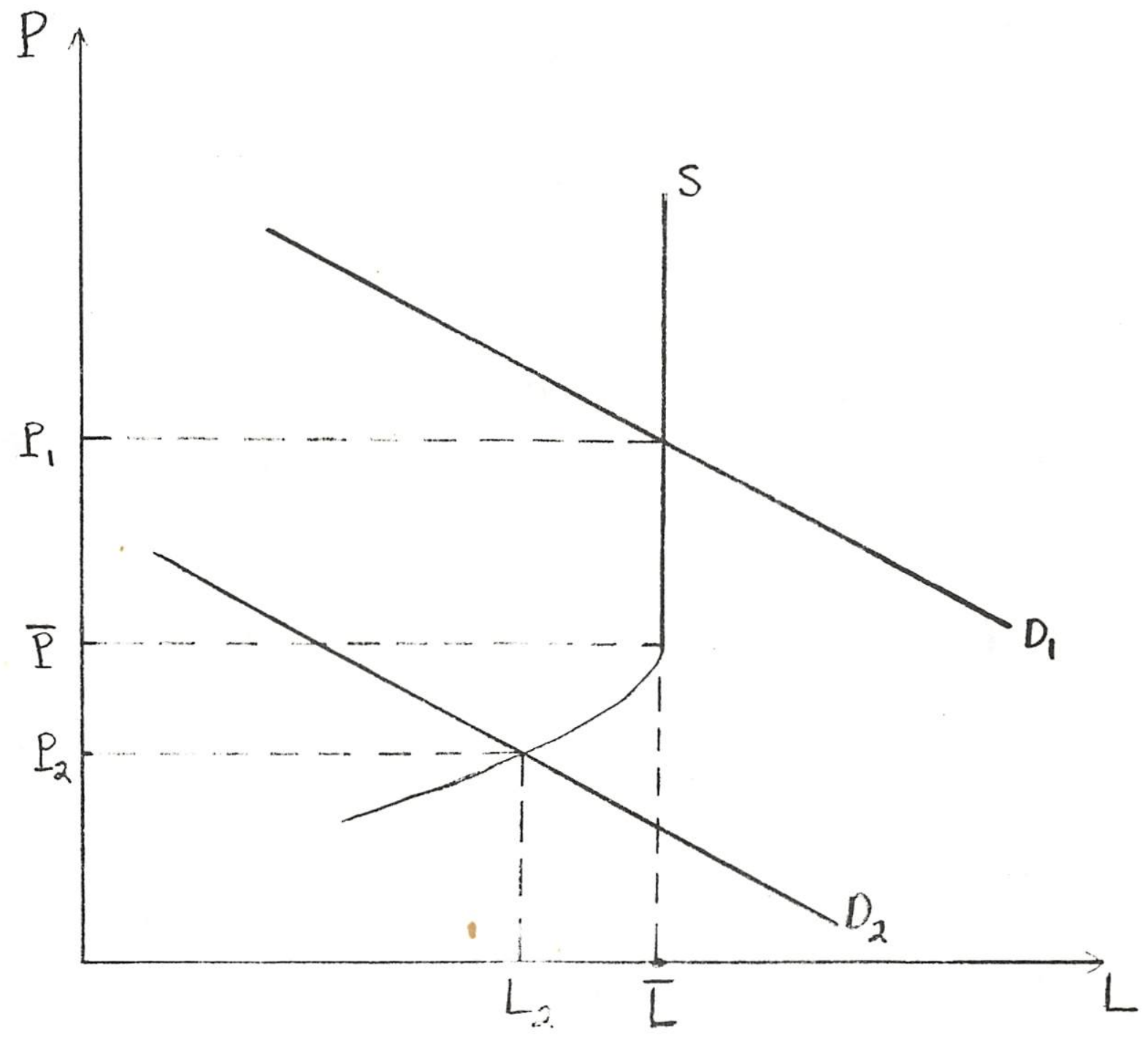

FIGURE I 
and land at one location is a very good substitute for land at another location, if the land at each location is physically similar. For simplicity let us assume that all recreational land is physically similar, and therefore such land differs only with respect to location. Furthermore, let us assume that all purchasers of such land live in the same city (e.g., Toronto). Under these assumptions, recreational land differs only with respect to distance from the city. Since the variation in distances of residential location within the city is very small relative to the variation in distances to cottages, for simplicity we will assume that all cottagers live in the centre of the city. Then all distances can be measured from the centre of the city.

Given these assumptions, it seems reasonable to construct a spatial model of the recreational land market along the lines of the typical models used to analyze urban land markets (see Dixit [1973], Mil1s [1972], and Solow [1973]). In those models the properties of the price (or rent) gradient of urban land is derived from a model in which urban land differs only with respect to distance from the central business district (CBD) and it is assumed every consumer must travel to the CBD to work. Some of the assumptions of these models are inappropriate for a model of the recreational land market, so we will construct a somewhat different model, although the basic features of the model closely follow Solow [1973].

Under our assumptions about the recreational land market, al1 consumers live in the same urban area, and recreational land differs only with respect to distance from the urban area. For simplicity let us assume that all consumers of recreational land living in the urban area (not necessarily all consumers living in the urban area) have identical tastes and income. 
Each consumer of recreational land consumes a composite consumption good, $z$ (encompassing all goods other than recreational land), and recreational land, s. One of the defects of the standard urban model for our purposes is the assumption that the number of trips taken is constant. Unlike urban workers, who must make a round trip to their job every working day, the cottager can vary the number of trips he takes each year. To allow for this possibility, let us assume the representative consumer's utility function is of the form

$$
U=U(z, s, \alpha)
$$

where $z$ is a composite consumption good, $s$ is the number of units of recreational land, and $\alpha$ is the number of round trips to the cottage taken per year. The number of trips, $\alpha$, is in the utility function to indicate that the more trips he takes, the more time he spends at the cottage, so that $U_{\alpha}>0$. The consumer could perhaps trade-off between the number of trips and duration of trips, but for most consumers this is not important since the work schedule determines the possible duration of a trip to the cottage, so we will ignore this possibility.

The budget constraint of the consumer is

$$
z+r(x) s+\alpha T(x)=y
$$

where $r(x)$ is the rent per unit of recreational land at distance $x$ (although we will talk about the rental rate on recreational 1and, prices of course can be determined by appropriate capitalization), the price of the consumption composite is taken to be unity, and $T(x)$ is the total travel cost of one round trip to land at distance $x$. The maximization of (1) subject to the budget constraint gives an indirect utility function of the form 


$$
V(r(x), T(x), y)
$$

As in the standard urban model, all identical consumers must get the same utility in equilibrium, so

$$
V(r(x), T(x), y)=\bar{v}
$$

Equation (4) determines the equilibrium rent gradient, given $\bar{v}$, which we can write

$$
r=r(x, T(x) ; \bar{v})
$$

Differentiating (4), and using the properties of indirect utility functions:

$$
\begin{aligned}
& \partial r / \partial \bar{v}=1 / V_{r}<0 \\
& \partial r / \partial x=-V_{T} / V_{r} T^{\prime}=-\alpha / s T^{\prime}<0
\end{aligned}
$$

(Recall from the standard urban model that if the number of trips is not subject to choice, $\partial r / \partial x=-T^{\prime} / \mathrm{s}$.)

Let $S(r(x), T(x), \bar{v})$ and $A(r(x), T(x), \bar{v})$ be the compensated demand functions for 1 and and trips. Then by (4), the equilibrium rent gradient is such that $s(r(x), T(x), y)=S(r(x), T(x) ; \bar{v})$, and $\alpha(r(x), T(x), y)=$ $A(r(x), T(x) ; \bar{v})$, for all $x$. Differentiating $S$ and $A$ with respect to $x$ :

$$
\begin{aligned}
& d S / d x=S_{r} r^{\prime}+S_{T^{\prime}} T^{\prime} \\
& d A / d x=A_{r} r^{\prime}+A_{T^{\prime}} T^{\prime}
\end{aligned}
$$

$S_{r}$ and $A_{t}$ are necessarily negative since they are own-substitution effect terms. However, $S_{T}=A_{r}$ is a cross-substitution effect which may be of any sign in a three good world. Therefore it is possible, according to (8), that $\mathrm{dS} / \mathrm{dx}<0$. This would occur if land and trips (time spent at the 
cottage) are strong net complements $\left(S_{T} \ll 0\right)$. This seems very unlikely however, so we would expect that $d S / d x>0, d A / d x<0$.

For the standard urban model, the other two equilibrium conditions (besides (4)) require that everyone live somewhere (population is assumed to be fixed), and the rent at the boundaries be equal to the value of land in alternative use. Although the assumption that "everyone lives somewhere" seems fairly reasonable for an urban model, it is not appropriate in the recreational land market, since a viable option of each consumer is to not own recreational land. If we could incorporate many different types of consumers in our model, this could be adequately dealt with, but this would present great technical difficulties. We can keep the technical convenience of identical consumers, while allowing for the fact that not all consumers may buy land be rewriting the usual equilibrium condition as

$$
\int_{I}^{R} n(x) d x=N(\bar{v}), N^{\prime}(\bar{v})>0
$$

where $n(x)$ is the number of cottagers at distance $x, N(\bar{v})$ is the total number of cottagers. That the total number of cottagers is a function of $\bar{v}$ reflects the fact that the number of consumers who own recreational land is endogenous. The distance of the closest 1 and used for recreation is $I$, and the outer boundary of settled recreational land is $R$. As we will see, $I$ and $R$ are endogenous to our model.

If the number of people living between $x$ and $x+d x$ is $n(x) d x$ and the fraction of arc available for cottage development in that arc is $a(x)$, then

$$
n(x) s(x)=2 \pi a(x) x, s=s(r(x), T(x), y)
$$

so that $n(x)=2 \pi a(x) x / s(x)$. Therefore we can write (9) 


$$
2 \pi \int_{I}^{R} \frac{a(x) x}{s(x)} d x=N(\bar{v})
$$

Assuming that distance $I$ is within reasonable (urban) commuting distance from the city, recreational land at distance $I$ is also presumably suitable for use as residential land for urban commuters. Therefore the value of recreational land at distance $I$ is determined by the value of such land in alternative use, i.e., as residential land. Therefore the boundary condition determining $I$ is

$$
r(I, T(I) ; \bar{v})=u(I)
$$

where $u(x)$ is the relevant portion of the urban rent gradient. The urban rent gradient, $u(x)$, is taken to be exogenous to our model. This is reasonable because the proportion of the urban population who are cottagers is very small.

The final equilibrium condition of the model is the boundary rent condition at $R$, which we will write

$$
r(R, T(R) ; \bar{v})=\bar{r}
$$

where $\vec{r}$ is the value of distant recreational land in alternative use (e.g., forestry).

The complete set of equilibrium conditions of the model consists of (5), (11), (12) and (13) which jointly determine $\bar{v}, I, R$ and $r(x)$. In Figure II we depict the equilibrium rent gradient. For a given $\bar{v}, r(x)$ is determined (by (5)), which then determines I (by the intersection of $r(x)$ and $u(I)$ ), and $R$ (by the intersection of $r(x)$ and $\bar{r}$ ). The parameter $\bar{v}$ is 


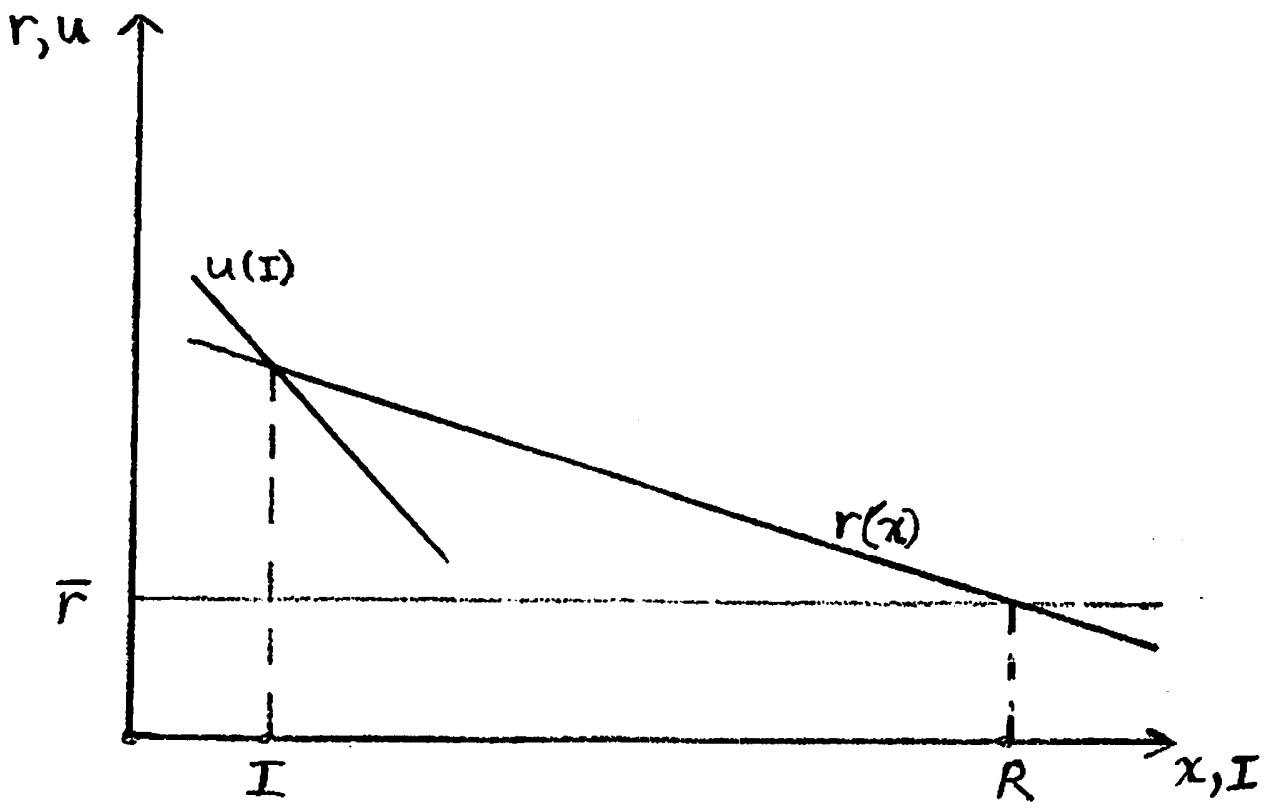

FIGURE II 
determined by (11). Notice that equilibrium requires that $r^{\prime}(I)>u^{\prime}(I)$. We will now discuss the effects of an increase in the costs of travel. A change in the costs of travel will affect both $r(x)$ and $u(x)$. In this section we will assume $u(x)$ is fixed. In the following section the effect on $r(x)$ of a change in $u(x)$ will be analyzed. The total effects of a change in $t$ on $r(x)$ can then be determined by combining the analyses of the two sections. For simplicity let us assume $T(x)=t x$. Then we can write (5)

$$
r=r(x, t ; \bar{v})
$$

with

$$
\partial r / \partial t=-\frac{V_{T} x}{V_{r}}=-\frac{x \alpha(x)}{s(x)}
$$

Differentiating (14) totally with respect to $t$, using (6) and (15),

$$
d r / d t=r_{t}+r_{\bar{v}} d \bar{v} / d t=-\frac{x a(x)}{s(x)}-\left[V_{y}(x) s(x)\right]^{-1} d \bar{v} / d t
$$

In the Appendix the comparative statics properties of the model are derived, and it is shown that $d \bar{v} / d t<0$, i.e., (equilibrium) consumer well-being falls with an increase in $t$. Notice that the simple partial equilibrium model of section II.A predicts that $d r / d t=-x \alpha(x) / s(x)$, since $-x \alpha(x) / s(x)$ is the change in travel costs (per "square foot") from a change in $t$. However, since $-d \bar{v} / d t$ is positive, the spatial model predicts that the change in transportation costs will always be less than fully "decapitalized" in land prices.

The effect of an increase in $t$ on the slope of the rent gradient can be determined from (16) by using the fact that $d / d t[d r / d x]=d / d x[d r / d t]$. 
Although the intuitive result is that an increase in travel costs will make the rent gradient steeper, examination of $d / d x[d r / d t]$ indicates that this is not necessarily the case. Let us assume, as seems reasonable in this context, that $V_{y}(x)$ (the marginal utility of income) is approximately constant (with respect to $x$ ), ${ }^{2}$ (or $V_{y}^{\prime}(x) \geqq 0$ ). Then, since $s^{\prime}(x)>0$, a sufficient condition for $d / d x[d r / d t](=d / d t[d r / d x])$ to be negative (i.e., for the rent gradient to become steeper) is that $d / d x\left[\frac{\alpha(x) \cdot x}{s(x)}\right] \geqq 0$. of course the sign of $d / d x\left[\frac{\alpha(x) \cdot x}{s(x)}\right]$ is an empirical issue which cannot be determined a priori. In the empirical section of this paper we provide some data which allow us to make some inferences about the sign of this derivative.

We can determine the percentage change in $r$ from (16):

$$
d r / d t \cdot 1 / r=\frac{1}{r(x) s(x)}\left[-x \alpha(x)-\left(v_{y}\right)^{-1} d \bar{v} / d t\right]
$$

Let us again assume that $v_{y}(x)$ is approximately constant (with respect to $x$ ) (or $V_{y}^{\prime}(x) \geqq 0$ ). Then, for example, if $d[x \alpha(x)] d x \geqq 0$ and $d[r(x) s(x)] / d x \leqq 0$, the percentage change in $r$ decreases (algebraically), which is consistent with the rent gradient becoming steeper. It is not necessarily the case however, that $r(x)$ shifts down everywhere, i.e., the new rent gradient may cut the original rent gradient from above $(d r / d t \cdot t / r>0$ for $x$ close to I). This is not implausible, since an increase in $t$ increases the relative attractiveness of near land, which could cause an increase in price. If $\mathrm{dr} / \mathrm{dt}>0$ for land near $\mathrm{I}$, and the percentage change in $r$ decreases (algebraically), the new rent gradient is necessarily steeper, at least to the left of where it cuts the original gradient.

In Figures III(a) and (b) we illustrate the two most intuitively 


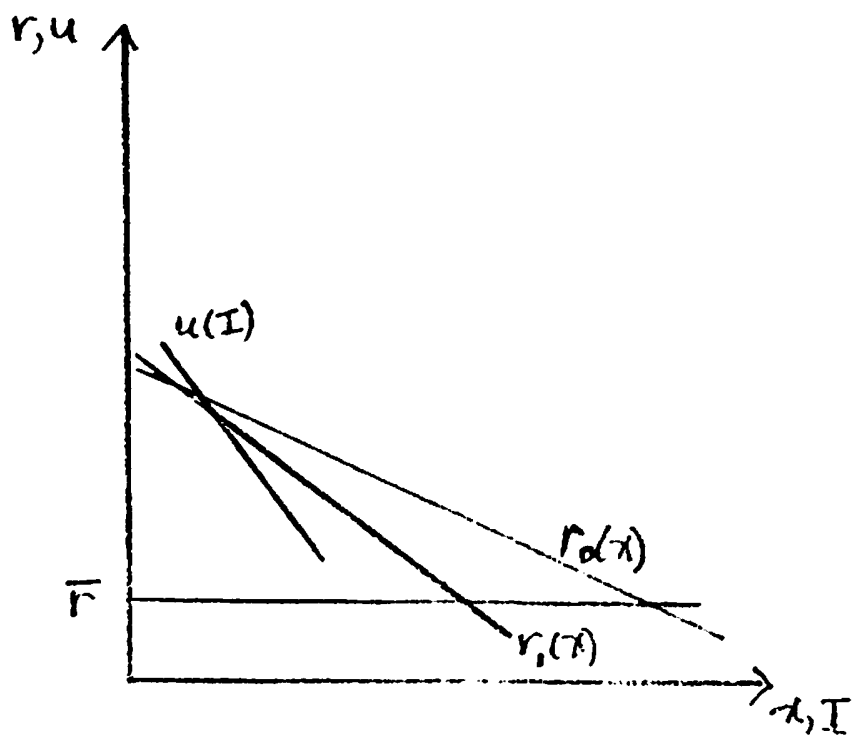

FIGURE III(a)

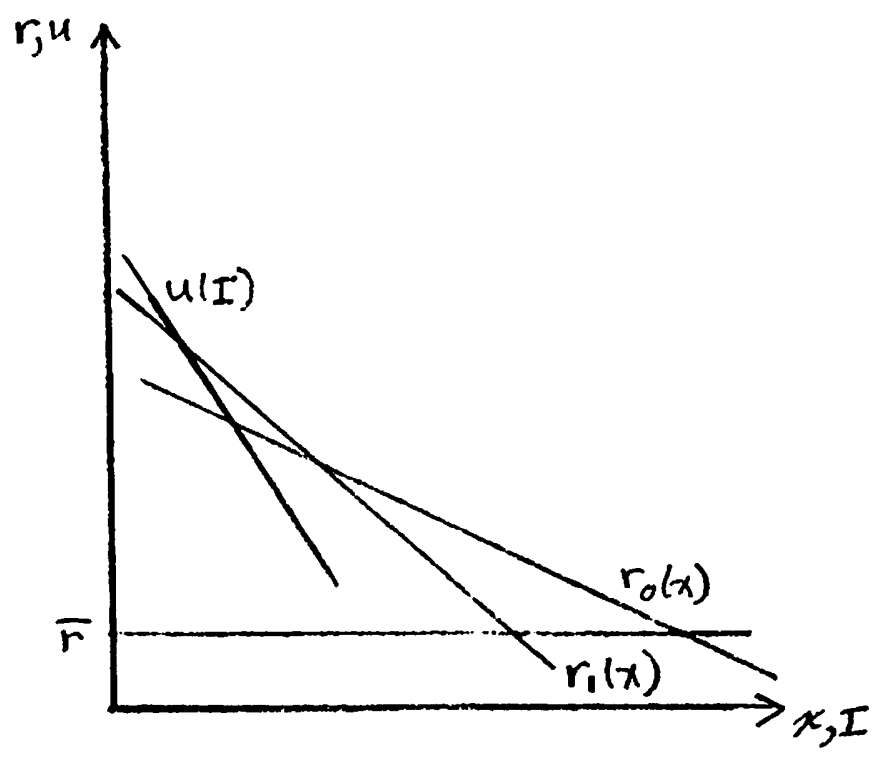

FIGURE III (b) 
plausible cases. In Figure III(a) we assume that the rent gradient shifts down everywhere, while in Figure III(b) we assume the new rent gradient custs the original one. In each case $r_{0}(x)$ is the original, and $r_{7}(x)$ the new rent gradient. To simplify our analysis we have assumed that $u(x)$ (the urban rent gradient) does not change. We would expect that the increase in $t$ would shift $u(x)$ (near I) down somewhat. We will analyze the effects of a shift in $u(x)$ in the following section.

Now let us consider the effect of a shift in the urban rent gradient (a dramatic upward shift has occurred in recent years in most Canadian cities). For technical convenience let us write $u(x)=\rho(x)+\theta$, and consider a shift in urban rent gradient arising from a change in $\theta .{ }^{3}$ From (5) and (6)

$$
d r / d \theta=\partial r / \partial \bar{v} d \bar{v} / d \theta=-\left[s(x) v_{y}(x)\right]^{-1} d \bar{v} / d \theta
$$

In the Appendix it is shown that $d \bar{v} / d \theta<0$, so an increase in $\theta$ unambiguously shifts up the equilibrium rent gradient.

From (18), the percentage change in $r$ at each $x$ can be written

$$
\frac{1}{r} d r / d \theta=-\left[V_{y}(x) r(x) s(x)\right]^{-1} d \bar{v} / d \theta
$$

Then if as before, we assume that $v_{y}(x)$ (the marginal utility of income) is approximatley constant, we see that the percentage change in $r$ is inversely related to $r(x) s(x)$. For example, if $r(x) s(x)$ is constant, an increase in $\theta$ will shift up the rent gradient by a constant proportion at each $x$. Let us define $\rho(x)$ and $\theta$ so that $\rho(I)=0$ at the original equilibrium. In this case $r(I)=\theta$ at the original equilibrium and $d \theta / \theta$ represents the percentage change in the urban price gradient at I. Then we can write (19)

$$
\frac{\theta}{r} d r / d \theta=\left[V_{y}(x) r(x) s(x)\right]^{-1} \theta d \bar{v} / d \theta
$$


If I did not change with $\theta$, it would have to be the case that $\theta / r d r / d \theta=1$, since $r(I)=\theta$ must then hold at the same I for the original and new $\theta$. In this case, assuming $v_{y}(x)$ and $r(x) s(x)$ are constant, a one per cent increase in $\theta$ would shift up the equilibrium rent gradient by one per cent at each $x$. However, an increase in $\theta$ will cause I to increase to $I_{1}>I$ which will mean that $r_{1}(I)<\rho(I)+\theta_{1}$, where $\theta_{1}$ is the new value of $\theta$, and $r_{1}(x)$ is the new recreational land price gradient. This will mean then that $\theta / r d r / d \theta$ at the original I (and at all $x$ if $V_{y}(x)$ and $r(x) s(x)$ are constant) is less than one. This is illustrated in Figure IV where $\overline{A C} / \overline{A I}_{0}$ is the percentage change in $\theta$ and $\overline{A B} / \overline{A I}_{0}$ is the percentage change in $r$ at the original $I, I_{0}$. ( $I_{1}$ was chosen arbitrarily, subject to $I_{1}>I_{0}$. ) We have drawn $r_{1}(x)$ under the assumption that $v_{y}(x)$ and $r(x) s(x)$ are constant (neither of these assumptions or the linearity of the gradients are necessary for the argument.

Finally, let us consider the effect of a change in transportation costs on the amount of travel. In another paper ${ }^{4}$ we have examined this problem in detail for the standard urban model. However, our analysis in that paper does not examine the relationship between the responsiveness of land prices to changes in travel costs and the responsiveness of travel to such changes. In our model the total mileage driven by all cottagers is

$$
D=2 \int_{I}^{R} x n(x) \alpha(x) d x
$$

The reduction in total travel resulting from an increase in $t$ is the result of two effects. First the increase in $t$ (ceteris paribus reduces the number of trips taken. Second, the increase in $t$ ceteris paribus shifts density towards the city. Presumably the magnitude of both these effects 


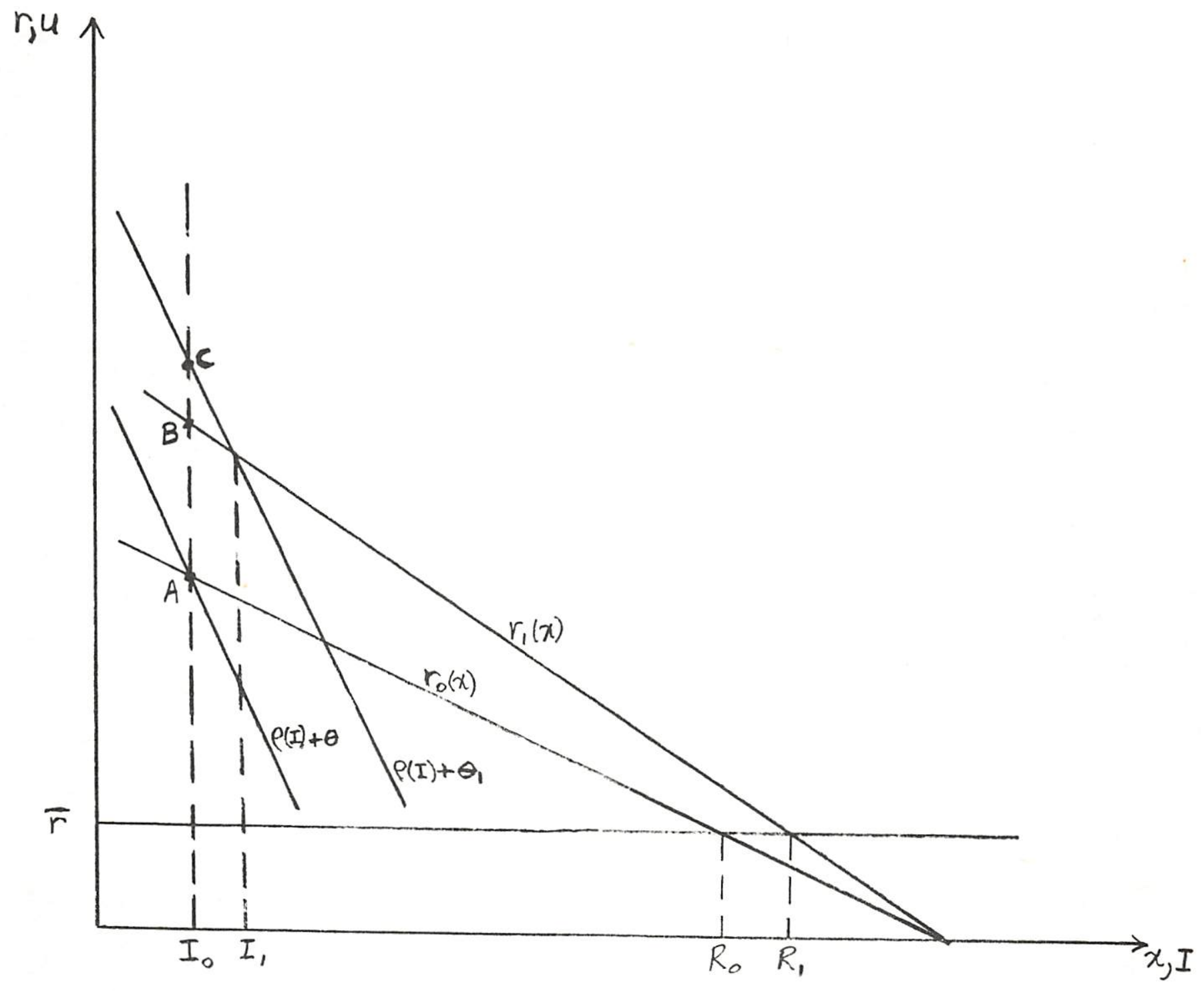

FIGURE IV 
is reduced in absolute value by the shift in the rent gradient. It is difficult however, to make this conjecture analytically precise. In the Appendix dD/dt is derived.

III. Gas Prices and the Ontario Cottage Land Market:

An Empirical Investigation

\section{A. Introduction}

The theory developed in section II was directed at determining the effects of an increase in travel costs and urban land prices and of travel to the change in travel costs. Of course, beginning somewhat after the Arab oil embargo of the U.S. in October 1973, there has been a significant increase in the price of gasoline (even in real terms) in Canada, so we have collected data on recreational land prices in Ontario to attempt to assess the effects of the increase in gas prices. Our research strategy was to estimate cottage land price gradients before and after the energy "crunch," and then to compare the two gradients to determine how cottage land prices have responded to the crunch. As we will see, this is a complicated problem, since the boom and crunch occurred almost contemporaneously.

Of course there have been changes in factors other than gas prices which affect the recreational land market. Compared to some of these, the actual change in real gas prices may seem fairly insignificant. However, since land is the most durable of goods, we would expect that the land market responds not only to short run changes in travel costs, but, more importantly, to expected long run changes. Since virtually all media coverage and government statements about the energy crunch have indicated 
that real gas prices will substantially increase in the near future, we would expect that agents in the land market are responding now to this presumed long run change. Because of this, despite the other "noise" affecting the land market, we would expect that the impact of higher gas prices would already be reflected in land prices. However, since it is difficult to assess to what extent the presumed future increase in gas prices is already reflected in the land market, it will be difficult to make very precise predictions about what the long run impact of the future increase will be.

\section{B. The Data}

To ensure as high a degree of homogeneity in the data as possible we confined our attention to lakefront cottage lots which had not yet been built on. This left us free of the knotty problem of how to deal with the inherent heterogeneity of structures.

Geographically, we confined our attention to Muskoka, Parry Sound and parts of Nippissing counties in Ontario. We chose these particular counties for two reasons. First, these counties account for a majority of the cottage development in Ontario. Second, by far the most common home residence of cottagers in these counties is the Toronto area or the U.S., and virtually all U.S. cottagers would commute to these counties via Toronto. Thus it is reasonable in these counties to use distance from Toronto as the relevant distance measure. We did not use counties east of these three because of the proximity of Ottawa. Conversations with Registry and Assessment officials in Nippissing County indicated that cottagers in that county generally have home residences in either the Toronto area or U.S., the Sudbury area, or North Bay. By consulting with these officials we 
restricted ourselves to areas of Nippissing County where the cottagers were predominantly from the Toronto area or the U.S.

Within the geographical area we have described, from Registry records we collected all transactions on vacant lakefront cottage lots on inland lakes which we could find in the records since 1972. We restricted ourselves to inland lakes, suspecting that cottage lots on Georgian Bay are inherently different from those on inland lakes. In an attempt to control for the amount of water access available, a few lots were excluded from the sample. Such lots were located along the large inland waterways of the Trent system, Lake Muskoka-Lake Joseph-Lake Rousseau, and Lake Nippissing. The lots in our sample are thus confined to those on inland medium-sized lakes. All transactions on Crown land were ignored, since the transactions prices generally bear no relationship to market prices. To maximize homogeneity in the sample, we also ignored transactions on island lots. The vast majority of transactions we recorded were on lots in registered cottage subdivisions, which is a reflection of the current institutional restrictions in the recreational land market. This likely also enhanced the homogeneity in the sample. As far as we could tell from the records and maps of subdivisions most of the lots in our sample were accessible by land.

The basic data collected on each transaction were sales price, frontage, and location. Data on acreage were available only for Parry Sound and Nippissing Counties, and therefore were not usable. ${ }^{5}$ From the location of each transaction and an Ontario road map we determined the distance from (downtown) Toronto, breaking the total distance down into three categories: travel on major, secondary, and county highways, which could serve as a proxy for differential travel time. 
Despite our attempts to impose homogeneity on the sample, significant variation in the price per frontage foot often existed on lots at approximately the same distance from Toronto, and sometimes on lots within the same subdivision! This is not surprising since features such as what end of the lake the lot is on, or if it is on a point, are very important. We would not, however, expect that these extra features are correlated with distance, which implies that the absence of data on these extra features should not introduce any significant bias in our results. 6

\section{Estimated Price Gradients}

From the data just described we estimated price gradients for 1973 and 1975 by using the transactions in those two years. After the usual specification search we settled on a logarithmic specification.

\section{The 1973 Price Gradient}

The estimated price gradient for 1973 was

$$
\begin{aligned}
& \text { LP73 }=\frac{10.6307}{(9.8379)}-\frac{.413681 \text { LTD73 }-\frac{1.0233 \text { LF73 }}{(2.08782)}}{(10.36)} \\
& R^{2}=.5878,87 \text { observations, t-statistics in parentheses } \\
& \text { LP73: Natural log of price per frontage foot } \\
& \text { LTD73: Natura1 log of total distance from Toronto } \\
& \text { LF73: Natural log of frontage }
\end{aligned}
$$

Frontage was included because of the presumed lumpiness of lot sizes due to topography. As mentioned in our discussion of the data, we had total distance broken down by type of highway, but the multicollinearity of the disaggregated distance variables and the similarity of results caused us to use only total distance. Total distance in the sample varied between 
138 and 225 miles. We see that the theoretically predicted negative relationship between price and distance is confirmed, and the frontage variable has the expected sign,

The analysis of section II indicated that the quantitative effects of an increase in transportation costs or an increase in urban land prices on the rent gradient would depend on how lot rents $(r(x) s(x))$ varied with distance, Therefore we regressed lot prices on distance giving us:

$$
\begin{aligned}
& \pi 73=\begin{array}{l}
6331.72 \\
(7.457)
\end{array}-\begin{array}{l}
10.125 \text { TD73 } \\
(-2.276)
\end{array} \\
& R^{2}=.0574 \\
& \pi 73: \text { Lot price } \\
& \text { TD73: Distance from Toronto }
\end{aligned}
$$

This regression indicates that lot prices fall with distance.

Finally, to see how lot size varied with distance we regressed LF73 on LTD73

$$
\begin{aligned}
& \mathrm{LF73}=\underset{(3.026)}{3.411}+\left(i^{273} \mathrm{LTD73}\right. \\
& \mathrm{R}^{2}=.01856
\end{aligned}
$$

2. The 1975 Price Gradient

The estimated price gradient for 1975 was

$$
\begin{aligned}
& \text { LP75 }=\underset{(13.2087}{(12.4516)}-\frac{1.13453 \text { LTD75 }}{(5.7661)}-\frac{.6578 \text { LF75 }}{(6.341)} \\
& R^{2}=.5783,67 \text { observations, t-statistics in parentheses }
\end{aligned}
$$

As in the 1973 regression, the coefficients have the expected signs. 
Notice that the coefficient on the distance variable in 1975 has increased in absolute value and also increased in significance over the 1973 coefficient. Distance varied in the sample between 138 and 225 miles.

The regression of LF75 on LTD75 resulted in

$$
\begin{aligned}
& \text { LF75 }=\underset{(2.842)}{3.4113}+\underset{(1.3375)}{.3109 \text { LTD75 }} \\
& \mathrm{R}^{2}=.0268
\end{aligned}
$$

Interpretation of the Results

In the following table we present in convenient form the predicted price per frontage foot at different distances for regression (22) and (24). To calculate the predicted prices we have set the frontage variable at the sample mean for 1973 (125 feet). In the model developed in section II.B, the consumption composite was taken as the numeraire. Therefore in column (3) of the table we have appropriately deflated the 1975 gradient by the CPI .

TABLE A

Distance
from Toronto

from Toronto

138

160

175

187

200

212

225
(1)

1973

Price

38.53

36.25

34.92

33.98

33.05

32.26

31.48
(2)

1975

Price

85.40

72.21

65.23

60.50

56.06

52.47

48.04
(3)

1975 Price

Deflated

by CPI

66.20

55.97

50.56

46.90

43.45

40.68

38.02 
If instead of setting the frontage variable equal to the sample mean, we use the predicted frontage equations (24) and (26) in calculating predicted price, we get

\section{TABLE B}

Distanc
from To

(2)

1975 Price

Deflated

by CPI

$\begin{array}{llll}138 & 41.49 & 79.08 & 61.27 \\ 160 & 37.45 & 64.87 & 50.26 \\ 175 & 35.19 & 57.53 & 44.57 \\ 187 & 33.61 & 52.64 & 40.78 \\ 200 & 32.08 & 48.11 & 37.28 \\ 212 & 30.81 & 44.50 & 34.48 \\ 225 & 29.57 & 41.09 & 31.84\end{array}$

The analysis of section II.B indicated that the qualitative effects on the rent gradient of an increase in travel costs would depend on how the demand for trips varied with distance. The only data we have been able to find which indicates how the number of trips vary with distance is found in the Analysis of Ontario Cottage Survey (1971). The data in this survey were compiled from the respondents to a 1968 questionnaire sent to approximately one per cent of all Ontario cottage owners with Ontario Hydro contracts. One of the questions asked was the number of weekends spent at the cottage during May to 0ctober. From that data we have condensed the following information. 


\section{TABLE C}

(1)

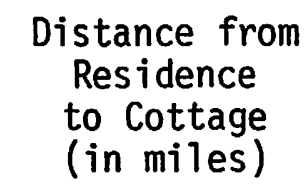

Distance from

to Cottage

(in miles)
(2)

51-100

101-150

151-200

$201-250$

$251-350$

$351-500$

12

11

16
(3)

Number of

Weekends

(Average of

Respondents '

Answers)
(4)

Number of

Weekends times

Midpoint of

Distance

Interval

$[\alpha(x) \cdot x]$
Respondents

$\begin{array}{rrr}94 & 16 & 1200 \\ 74 & 13 & 1625 \\ 30 & 11 & 1925 \\ 12 & 8 & 1800 \\ 11 & 7 & 1925 \\ 16 & 6 & 2550\end{array}$

1200

1625

1925

1800

The number of weekends spent at the cottage during May to October is probably a.good indication of the number of trips taken during the year. It underestimates the number of weekends spent during the whole year, but overestimates the number of trips taken between May and October. Therefore a reasonable proxy for $x \alpha(x)$ is column (3). On the basis of the data in Table C (given the very small number of respondents in the last three categories), it is reasonable to conclude that $d / d x[x \alpha(x)]>0$. If anything, these data probably understate the size of $d / d x\left[x_{\alpha}(x)\right]$ for the mid-1970's, since there have been significant improvements in the major highways in our sample area since 1968 (before our sample period) (particularly highways 400 and 11 , which the main routes to most of our sample area). As we saw in (16), to determine the effect of an increase in transportation costs on the slope of the price gradient, it was necessary to know the sign of $d / d x\left[x_{\alpha}(x) / s(x)\right]$. If we compute $x \alpha(x) / s(x)$ from (24) and column (4) of Table $C$, we get the following data. 
TABLE D

(1)

Distance from

Residence

to Cottage

(in miles)
(2)

$$
x \cdot \alpha(x) / s(x)
$$

\begin{tabular}{rr}
75 & 12.19 \\
125 & 14.36 \\
175 & 15.51 \\
225 & 13.54 \\
300 & 13.39 \\
425 & 16.13 \\
\hline
\end{tabular}

Recall from our discussion of (16) that a sufficient condition for an increase in transportation costs to make the price gradient steeper is $d / d x[x \alpha(x) / s(x)>0$. We see from Table $D$ that this sufficient condition holds, at least for distances up to 175 miles. Furthermore, as we pointed out earlier, we would expect that $d / d x[x \alpha(x)]$ was probably greater in 1973 than in 1968, the time of the survey. The entires in the last three categories of column (2) of Table $D$ are also suspect, given the very small number of respondents in these categories. Therefore the data (roughly) indicate that $d / d x[x \alpha(x)]>0$. Since this condition is sufficient (but not necessary) for a steepening of the price gradient, it is certainly safe to say that the data are consistent with the hypothesis that, ceteris paribus, an increase in travel costs would have made the 1973 price gradient steeper.

A comparison of columns (1) and (3) in Table A or B shows that the price gradient, deflated by the CPI, is steeper, but everywhere above the 1973 gradient for distances up to 225 miles. From the tables we can see that the 
1975 CPI deflated gradient would go below the 1973 gradient for distances somewhat in excess of 225 miles. Although our sample only included distances up to 225 miles, there is significant Toronto-U.S. based cottage development at distances in excess of 225 miles (for example, in the Lake Timagami Lake Timiskaming area, which is approximately 300 miles from Toronto). The model of section II.B indicated that a change in travel costs is likely to shift the gradient so that it cuts the original gradient from above (such as in Figure III(b)). Therefore the change in the gradient from 1973 to 1975 (deflated) is not inconsistent with a hypothesis that this change was a result of a change (actual, and expected future) in gas prices.

However, the difference between columns (1) and (3) seems too large to be able to argue comfortably that the energy crunch was the only cause. In terms of the model developed in section II.B, assuming tastes are constant, the other factors which could cause a rise in the rent gradient are an increase in $y, N, \bar{r}$ or $U(x)$. The recent recessions experienced by the Canadian and U.S. economies would seem to preclude arguing that an increase in income was a significant factor during our sample period. For example, average weekly earnings in Canada rose only $1 \%$ in real terms during our sample period. The number of people older than, say, 35, has grown in Ontario and the U.S. over our sample period, but not at a rate which would explain the shift in the price gradient. Finally, there is no reason to suppose that $\bar{r}$ (the value of the most distant recreational land in alternative use) has increased faster than the rate of inflation.

There have been two important institutional changes during the period which could have had a significant impact on the recreational. land 'market. These are the Ontario Land Transfer Tax and the Ontario Land Speculation Tax, both enacted in April 1974. The Land Transfer Tax Act 
1evies a $20 \%$ tax on foreign purchasers of Canadian land (as opposed to a .75 levy on residents). This tax would presumably reduce U.S. demand for Ontario recreational land which would tend to offset the effects of income and population increases in Toronto. The Land Speculation Tax Act levies a capital gains tax on real estate transactions excluding a person's principal residence and principal recreational residence. This of course increased the relative attractiveness of recreational land as an investment, which could stimulate demand. However, as far as we could determine from conversations with Registry and Assessment officials, and from observation of the turnover frequency of cottage lots during the period, the Land Speculation Tax has probably not had a significant impact on the recreational land market.

We must therefore conclude that the net effect of changes in income, population, and government regulation alone are not likely to have been large enough to account for the actual change in the recreational land price gradient. Furthermore, it seems completely unlikely that the net effect of these changes alone could have produced the marked steepening of the 1975 gradient. What then is the explanation for the extent of the actual change? We believe the explanation can be found in an examination of what happened to residential lot prices in this period. For reasons having little to do with the energy crunch, urban residential lot prices increased by more than the CPI during this period. ${ }^{7}$ For example, residential lot prices in the Barrie/Orillia area (which is at the outer edge of the urban price gradient) increased by about $65 \%$ during the period. In terms of the model of section II.B, this would affect recreational land prices through an upward shift in the urban price gradient.

According to the analysis of section II, an upward shift in the urban 
price gradient $(u(x))$ will shift up the recreational land price gradient. Equation (20) and the accompanying analysis, indicates that the quantitative effect will depend on the percentage change in urban prices at I, and how $r(x) s(x)$ varies with distance. Regression (2) indicates that $r(x) s(x)$ falls with distance. Therefore, the analysis predicts that ceteris paribus, the increase in urban land prices should have raised the recreational land price gradient, and flattened it relative to a constant percentage increase. Using the analysis of section II we could, with sufficient data, determine what the 1975 price gradient would have been if there had been only a change in urban land prices (and the inflation in the CPI). We could calculate this ceteris paribus 1975 price gradient using (20) and (23) if we assumed the marginal utility of income is constant, and if we knew what the ceteris paribus percentage change in price would have been at the 1973 I. This could be done since from (20), if $p$ is known to be the percentage change at some distance $\bar{x}$, then $[p r(\bar{x}) s(\bar{x})] /[r(x) s(x)]$ is the percentage change at any $x$. Our discussion of (20) indicated that the percentage change in price at the original I would be less than the percentage change in urban land prices at the original I. As we mentioned earlier, the change in urban land prices in the Barrie-Orillia area was about $65 \%$. In terms of our mode1, the location of I in 1973 was somewhat north of Orillia. Therefore the change in urban land prices at the original (1973) I was probably somewhat less than $65 \%$.

Since our sample data are north of I, to. calculate what the ceteris paribus 1975 price gradient would have been, we would need to know what the ceteris paribus percentage change in prices would have been for land at 138 miles from Toronto (the southern-most observations in our sample). We know of no way in which we can estimate this. However, we do know it 
is probably less than $65 \%$ and more than the change in CPI, $29 \%$. For purposes of exposition, let us assume that the percentage change in prices at 138 miles would have been $60 \%$. Under this assumption (and assuming the marginal utility of income is constant) we can calculate the ceteris paribus 1975 gradient using (2) and regression (23). First, we must inflate the 1973 price gradient by the CPI (1.29). Then since we assume the rate of increase in price at 138 miles would have been $60 \%$, ceteris paribus, this is an increase of $24 \%$ over the CPI inflated value. Then, for example, to calculate the ceteris paribus 1975 price at 200 miles, we calculate the ratio of the 1973 lot price at 138 miles to the 1973 lot price at 200 miles from regression (23) $(\pi 73(138) \div \pi 73(200))$. Let us call this ratio $B_{200}$. Then, according to (20), the percentage change in price at 200 miles should be this ratio times the percentage change in prices at 138 miles (assumed to be $24 \%$ ), i.e., $B_{200} \times .24$. Finally, the ceteris paribus 1975 price at 200 miles is then equal to the $1973 \mathrm{CPI}$-inflated price at 200 miles $(1.29 \times 32.08$, where 32.08 is from Table B) times $\left(1+\beta_{200} \times .24\right)$.

In the following table we calculate the ceteris paribus 1975 price gradient using this method. The entries for the 1973 price and the 1975 price are the same as those in Table B.

Since we have already argued that the net effect of changes in variables other than travel costs and urban land prices is likely to have been small, the difference between columns (3) and (2) in Table E can be argued (conditional on our estimate that the percentage change in prices at 138 miles would have been $60 \%$, ceteris paribus) to have been caused by the energy crunch. A comparison of columns (2) and (3) shows that the predictions are qualitatively correct, in that the 1975 price gradient is steeper than the 1975 ceteris paribus price gradient. One way of checking 
TABLE E

(1)

\begin{tabular}{r}
$\begin{array}{r}\text { Distan } \\
\text { from } \\
\text { Toron }\end{array}$ \\
\hline 138 \\
160 \\
175 \\
187 \\
200 \\
212 \\
225
\end{tabular}

(2)

(3)

1975

Ceteris

Paribus

Price

66.38

60.87

57.20

54.95

52.77

51.01

49.29

the credibility of the entries in column (3) is to recall from (16), that the theory predicts that the increase in travel costs will never be fully "decapitalized" in land prices.

For example, let us consider a cottager with a 125 foot lot at a distance of 200 miles from his residence in Toronto. According to a comparison of columns (2) and (3) the price of a 125 foot lot 200 miles from Toronto would (controlling for urban land prices) have fallen, ceteris paribus, by $\$ 582.50$. The average price per gallon of gasoline in Toronto was $\$ .56$ in 1973, and approximately $\$ .80$ in 1975 . Assuming he drives a car which gets 15 miles per gallon, the cost of a round trip to the cottage increased by $\$ 6.40$. If he makes ten round trips per year, then the change in yearly travel cost is $\$ 64.00$. Assuming a $5 \%$ rate of inflation, and a discount rate of $12 \%$, the present value of this change in travel costs is $\$ 1024$, which is larger than the predicted ceteris paribus fall in lot value. If we do the same calculation for a cottager with a 133 foot lot 
(predicted by (24)) 225 miles from Toronto, the predicted ceteris paribus fall in lot price is $\$ 1090.60$ and the capitalized change in transportation costs is $\$ 1152.00$. These calculations almost certainly understate the magnitude of difference between the change in lot prices and the capitalized change in travel costs since presumably the price gradient partially reflects the expected future price of gas. For example, if the gas price is expected to rise soon to at least $\$ 1.00$ per gallon (a commonly quoted figure in public discussion), the capitalized change in transportation costs for a cottager at 225 miles is $\$ 2112$. Of course these calculations are sensitive both to the precision of the estimates in regressions (22) and (23) and to our assumption that the percentage change in price at 138 miles would have been $60 \%$, ceteris paribus. However, these examples should indicate that the entries in column. (3) are not unreasonable.

In conclusion, the data support the theoretical predictions of how recreational land prices will be affected by a change in travel costs. However, the recent increase in urban land prices has significantly increased recreational land prices, which, combined with the increase in gas prices could have a significant effect on recreational travel. If, as we would predict, ${ }^{8}$ real urban.land prices fall to approximately their previous level, our results suggest that the response of recreational land prices to changes in gas prices will moderate the effect of gas price increases on recreational travel. 
APPENDIX

The three equilibrium conditions of the model are

$$
\begin{aligned}
& 2 \pi \int_{I}^{R} \frac{a(x) x d x}{S(r(x) t ; v), t ; \bar{v})}=N(\bar{v}) \\
& r(I, t ; \bar{v})=\rho(I)+\theta \\
& r(R, t ; \bar{v})=\bar{r}
\end{aligned}
$$

Totally differentiating the equilibrium conditions,

$$
\begin{aligned}
& \frac{2 \pi a(R) R}{S(R)} d R-\frac{2 \pi a(I) I}{S(I)} d I-2 \pi\left[\int \frac{a(x) x\left[S_{r} r_{\bar{v}}+S_{\bar{v}}\right]}{s^{2}}+N^{\prime}\right] d \bar{v} \\
& =2 \pi\left[\int \frac{a(x) x\left[S_{r} r_{t}+S_{t}\right]}{s^{2}} d x\right] d t \\
& {\left[r_{x}(I)-\rho^{\prime}(I)\right] d I+r_{\bar{v}}(I) d \bar{v}=-r_{t}(I) d t+d \theta} \\
& r_{x}(R) d R+r_{\bar{v}}(R) d \bar{v}=-r_{t}(R) d t+d \bar{r}
\end{aligned}
$$

Since equilibrium requires $\left[r_{x}(I)-\rho^{\prime}(I)\right]>0$, the only term ambiguous in sign is $2 \pi\left[\int \frac{a(x) x\left[s_{r} r_{t}+s_{t}\right]}{s^{2}} d x\right]$. The problem here is the sign of $s_{t}$. If we assume $S_{t}$ is "small", or that space and trips are gross substitutes (i.e., $S_{t}>0$ ) then this term is positive.

Under these assumptions, using (30), (31) and (32), it can easily be 
shown that $d \bar{v} / d t, d \bar{v} / d \theta$, and $d \bar{v} / d \bar{r}$ are all negative. It can also be shown that $d I / d \theta>0, d I / d \bar{r}<0, d R / d \theta>0, d R / d \bar{r}<0$.

Now we will examine the effect of an increase in $t$ on $D$. From (18)

$$
\begin{aligned}
\mathrm{dD} / \mathrm{dt} & =2 \mathrm{Rn}(\mathrm{R}) \alpha(\mathrm{R}) \mathrm{dR} / \mathrm{dt}-2 \mathrm{In}(\mathrm{I}) \alpha(\mathrm{I}) \mathrm{dI} / \mathrm{dt} \\
& +2 \int_{I}^{R} x[\alpha \mathrm{dn} / \mathrm{dt}+\mathrm{nd} \alpha / \mathrm{dt}] \mathrm{dx}
\end{aligned}
$$

where $n(x)=2 \pi a(x) / s(x)$,

$$
\mathrm{dn} / \mathrm{dt}=\partial n / \partial r \mathrm{dr} / \mathrm{dt}+\partial \mathrm{\partial n} / \partial t, \quad d \alpha / d t=\partial \alpha / \partial r \mathrm{dr} / \mathrm{dt}+\partial \alpha / \partial t
$$

The first two terms in (33) indicate the change in $D$ resulting from ceteris paribus changes in $R$ and I respectively. The term $2 \int(x \alpha d n / d t) d x$ indicates the change in $D$ resulting from a ceteris paribus change in density. Finally, the term $2 \int(x n d \alpha / d t) d x$ indicates the change in $D$ resulting from a ceteris paribus change in trips. 


\section{FOOTNOTES}

*This research was funded by the General Motors Corporation, whose support we gratefully acknowledge. The views expressed in this paper are exclusively those of the authors.

'Research assistance was provided by Paul Boothe, Heather Cohen, and John Gartenburg. Officials at the Muskoka and Nipissing-Parry Sound Regional Assessment Offices were very helpful to us, as were Henry Joseph and Larry Fortin of A.E. Lepage.

${ }^{1}$ We have used the fact that $s(x)=-V_{r} / V_{y}$.

${ }^{2}$ The justification of this assumption is that the proportion of income spent on recreational land is presumably small.

${ }^{3}$ Considering a shift in $u(x)$ of this type is purely for technical convenience. All of the following results are consistent with any general inward or outward shift of $u(x)$.

${ }^{4}$ Robson and Scheffman [1976].

${ }^{5}$ This is probably not important because in most cases there is a close relationship between frontage and acreage. For example, assessments in these counties are levied on frontage foot.

${ }^{6}$ The argument here is that although we have left out variables. in our regressions, since they are not correlated with the included regressors, the coefficients of the included regressors are still unbiased. 
$-35-$

${ }^{7}$ For an explanation of the rise in urban land prices see Markusen and Scheffman [1977].

${ }^{8}$ See Markusen and Scheffman [1977]. 


\section{REFERENCES}

Analysis of Ontario Cottage Survey, Travel Research Report No. 55, Ontario Department of Tourism and Information, 1971.

Cicchetti, C., Seneca, J., and Davidson, P., The Demand and Supply of Outdoor Recreation, Bureau of Outdoor Recreation, Washington, 1969.

Clawson, M., and Knetsch, J., Economics of Outdoor Recreation, Johns Hopkins, 1966.

Dixit, A. K., "The Optimum Factory Town," Bell Journal of Economics and Management Science 4, 637-651, 1973.

Markusen, J. R., and Scheffman, D. T., Urban Land Development: Speculation and Market Structure, University of Toronto Press, 1977.

Mills, E. S., Studies in the Structure of the Urban Economy, Johns Hopkins Press, Baltimore, 1972.

Mohring, H., "Spatial Equilibrium in a CBD-Oriented City," unpublished paper, 1969.

Montesano, A., "A Restatement of Beckmann's Model on the Distribution of Urban Rent and Residential Density," Journal of Economic Theory 4, 329-354, 1972.

Ontario Recreation Survey: Tourism and Outdoor Recreation Planning Study -Progress Report No. 2, Ontario Minsitry of Industry and Tourism, 1974. 
Ontario Tourism Statistical Handbook 1975, Ontario Ministry of Industry and Tourism, 1975.

"A Report on the Disposition of Public Land for Cottage Purposes in Ontario, Other Canadian Provinces and Neighboring States," Ontario Department of Lands and Forests, 1971.

Robson, A. J., and Scheffman, D. T., "Urban Structure, Gas Prices, and the Demand for Transportation," manuscript, 1976.

Solow, R. M., "Congestion, Density and the Use of Land in Transportation," Swedish Journal of Economics 74, 161-172.

Solow, R. M., and Vickery, W., "Land Use in a Long Narrow City," Journal of Economic Theory $3,430-447$.

Solow, R. M., "On Equilibrium Models of Urban Location" in Essays in Modern Economics, M. Parkin and A. R. Nobay (eds.); Longmans (1973). 


\author{
RESEARCH PROGRAM: \\ IMPACT OF THE PUBLIC \\ SECTOR ON LOCAL ECONOMIES
}

The Department of Economics, University of Western Ontario, has recently mounted a long-term research program on the Impact of the Public Sector on Local Economies. The program publishes Discussion Papers and Research Studies. Copies may be obtained by writing:

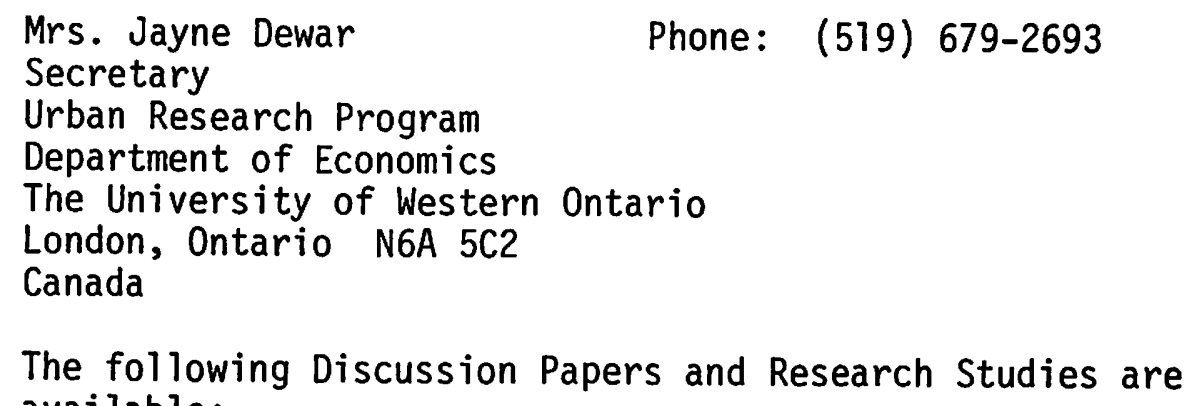

The following Discussion Papers and Research Studies are

\title{
DISCUSSION PAPERS:
}

* 001 P.T. Chinloy, "Hedonic Prices and Age Deterioration in Urban and Suburban Housing" (September 1975). [30 pp. - \$1.50]

002 M.W. Frankena, "Alternative Models of Rent Control" (September 1975).

003 J.R. Markusen and D.T. Scheffman, "Ownership Concentration and Market Power in Urban Land Markets" (October 1975).

004 A.J. Robson, "The Effect of Urban Structure on Ambient Pollution" (October 1975).

005 J.R. Markusen and D.T. Scheffman, "The Timing of Residential Land Development: A General Equilibrium Approach" (November 1975).

006 A.J. Robson, "Cost-Benefit Analys is and the Use of Urban Land for Transportation" (December 1975).

007 M.F. Goodchild and P.J. Booth, "Modelling Human Spatial Behavior in Urban Recreation Facility Site Location" (January 1976).

008 M.W. Johnson, "Consumer Location and Local Public Goods" (March 1976).

009 K.L. Avio and C.S. Clark, "The Supply of Property Offenses in Ontario" (April 1976). 
010 P.T. Chinloy, "Depreciation, Adverse Selection and Housing Markets" (May 1976).

011 C.L. Poon, "An Economic Evaluation of Urban Railway Relocation" (September 1976).

012 A.J. Robson, "Income Uncertainty and Urban Location" (September 1976).

013 M.W. Frankena, "An Error in Estimating Urban Density Functions Using Census Tract Data" (October 1976).

014 G.W. Davies, "The Demand for Automobiles in Canada" (December 1976).

015 M.W. Frankena, "The Demand for Urban Bus Transit in Canada" (December 1976).

016 A.J. Robson and D.T. Scheffman, "The Crunch, the Boom, and the Recreational Land Market" (January 1977).

017 A.G. Blomqvist and W. Haessel, "Small Cars, Large Cars, and the Price of Gasoline" (January 1977).

\section{RESEARCH STUDIES:}

01 G.W. Davies and P.L. Jackson, "A Model of the Urban Housing and Residential Land Markets" (September 1975).

02 G.P. Schaefer, "The Urban Area Production Function and the Urban Hierarchy: The Case of Saskatchewan" (October 1975).

03 C.L. Poon, "A Cost-Benefit Study of Urban Railway Relocation" (November 1976).

*This report is out-of-print. Xerox copies can be obtained for a minimal charge of $5 \$$ per page. 